\title{
Agricultura urbana e agroecologia \\ no território do extremo sul do município de São Paulo
}

\author{
ANGÉLICA CAMPOS NAKAMURA ${ }^{I}$ \\ e VALERIA DE MARCOS ${ }^{I I}$
}

\section{As origens da agricultura no extremo sul do município de São Paulo}

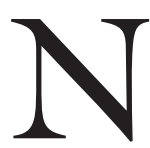
OS Últimos ANOS, o extremo sul do município de São Paulo começou a ganhar mais atenção por parte do poder público, da mídia e da socieda-

de civil. Essa região, que abriga agricultores convencionais e orgânicos, aldeias indígenas, sítios de lazer, atividades de turismo como cachoeiras, parques municipais, duas Áreas de Proteção Ambiental (as APA Capivari-Monos e Bororé-Colônia) e templos abertos à visitação, não é muito conhecida pelas pessoas do próprio município. Ela é composta pelos distritos de Marsilac, Parelheiros e Grajaú, e desde o início dos anos 2000 várias políticas públicas têm sido ali implantadas, especialmente as pensadas para estimular a agricultura orgânica e agroecológica.

Apesar da legislação, de políticas públicas e interesse de diferentes setores pela agricultura presente no extremo sul, ela não é uma atividade recente. Aroldo de Azevedo, em sua tese de concurso à cátedra de Geografia do Brasil da Faculdade de Filosofia da Universidade de São Paulo, de 1945, já apontava a presença da agricultura nessa região, reconhecendo-a como uma área suburbana. ${ }^{1}$ Ali, a mancha urbana paulistana que crescia rapidamente não havia chegado. De acordo com Azevedo, as represas e a escarpa da Serra do Mar serviam como barreiras para o avanço da metrópole (apud Penteado, 1958, p.6).

A presença da agricultura, porém, ganhou mais força com a chegada de imigrantes, em especial dos japoneses, no início do século XX, os quais passaram a se dedicar, principalmente, à horticultura. Até então, a agricultura praticada era a conhecida como caipira. Hoje, essa agricultura ganhou uma nova roupagem e passou a ser conhecida como orgânica ou agroecológica, tornando-se mais valorizada, pois é vista como ambientalmente mais correta e sustentável.

Contudo, se hoje a antiga agricultura caipira é tida como melhor para o meio ambiente e a saúde das pessoas - agricultores e consumidores -, na época 
da chegada dos imigrantes, ela era vista de forma preconceituosa por pesquisadores que acompanhavam o desenvolvimento dessa região. É o caso de Costa (1958, p.116, 117 e 123), por exemplo, que faz referência aos caipiras com desdém, como pessoas que não sabiam aproveitar o solo, produzir, auferir lucros, utilizavam técnicas rudimentares e faziam canteiros assimétricos e desalinhados. Como contraponto, a autora fala dos japoneses com admiração e elogia sua forma de produção, pois utilizavam arados, produtos para combater as pragas, sementes selecionadas e montavam canteiros em linhas geométricas, que lembravam técnicas de jardinagem.

Mesmo se transformando e ganhando importância, a agricultura foi deixada de lado, perante o enorme crescimento da metrópole paulistana ao longo do século XX, ao mesmo tempo em que foi sendo esquecida por grande parte dos cidadãos e pelo próprio poder público. Desde então, a mancha urbana cresceu e alcançou esse extremo sul do município. Entretanto, as represas Billings e Guarapiranga ainda se apresentam como barreiras para a ampliação mais rápida dessa mancha.

A partir dos anos 2000, porém, várias Organizações não Governamentais $(\mathrm{ONG})$ começaram a atuar no território e diversas políticas públicas surgiram a fim de incentivar e fortalecer uma agricultura agroecológica para a conservação da vegetação nativa e dos mananciais, barrar o crescimento da mancha urbana e, ainda, fornecer alimento para a cidade. Com as trocas de gestão mais recentes, a quantidade de políticas diminuiu nos últimos anos, reflexo de uma mudança de interesse dessas gestões. Na atualidade, aquela que mais tem se destacado é o Projeto Ligue os Pontos, ainda em andamento, que vem tentando fortalecer a produção e a comercialização de agricultores agroecológicos.

\section{As ações e políticas públicas no território \\ para uma agricultura agroecológica a partir dos anos $\mathbf{2 0 0 0}$}

Foi apenas com a aprovação do Plano Diretor ${ }^{2}$ do município de São Paulo em 2002, por meio da Lei n.13.430, na gestão de Marta Suplicy, que a agricultura praticada na metrópole começou a receber mais atenção. Nele, encontram-se referências à agricultura, aqui denominada como agricultura urbana, mas não se faz diferença entre a agricultura intraurbana e a periurbana, ou seja, entre a agricultura praticada dentro da cidade e aquela praticada em uma área rural, dentro dos limites do município. Também nesse Plano, fica claro que, para o poder público municipal, a agricultura urbana poderia servir como ferramenta de combate à fome e exclusão social, à criação de organizações e atividades solidárias e associativas para sua produção e comercialização de gêneros agrícolas, e como atividade produtiva que poderia ocupar terrenos públicos ociosos. Porém, esse plano não delimitou, de fato, uma zona rural, apenas ressaltou a importância da atividade agrícola para o município.

Com a inclusão da agricultura urbana no Plano Diretor, surge uma lei que é considerada um marco para as políticas públicas voltadas para a agricultura no mu- 
nicípio de São Paulo: o Programa de Agricultura Urbana e Periurbana (Proaurp), lançado pela Lei n.13.727 em 2004 e regulamentado pelo Decreto n.51.801 em 2010. A partir do Proaurp, observa-se o surgimento de iniciativas pensadas para a agricultura, entre as quais a criação da Casa de Agricultura Ecológica (CAE) José Umberto Macedo Siqueira, no distrito de Parelheiros, a qual foi oficializada por meio do Decreto n.47.280, pelo então prefeito Gilberto Kassab. A CAE está em funcionamento até os dias atuais, e conta com funcionários que dão assistência técnica aos agricultores da região, sejam eles do município de São Paulo, sejam dos municípios vizinhos, como Embu-Guaçu e São Bernardo do Campo, não importando se realizam uma agricultura convencional ou agroecológica.

A vinculação da agricultura a uma prática mais sustentável já aparece no Plano Diretor de 2002, pois a atividade agrícola aparece relacionada com o uso sustentável dos recursos e a conservação da natureza. No Proaurp, essa postura fica ainda mais clara, pois seu objetivo é "incentivar e apoiar a produção agroecológica e a comercialização na cidade de São Paulo" (Cidade de São Paulo, 2013). Com essa preocupação em estimular a expansão da produção agroecológica, presente nas leis do município, surgiram iniciativas para incentivar agricultores do extremo sul a substituírem os cultivos convencionais por aqueles orgânicos e agroecológicos.

Esse foi um período bastante fértil para a agricultura desenvolvida na região. Várias ONG, como Instituto Kairós, Instituto Pedro Matajs, 5Elementos e a própria Universidade de São Paulo, por meio da Incubadora Tecnológica de Cooperativas Populares (ITCP), atuaram com projetos voltados para a transição agroecológica, agricultura orgânica e comercialização solidária no período entre 2007-2012, e algumas dessas ONG continuam presentes ainda hoje na região. Os agricultores ali situados passaram a participar de vários projetos voltados para essas diferentes finalidades, ampliando o conhecimento e as redes de colaboração e parceria entre eles. Muitas dessas ONG, e a própria ITCP-USP, possuíam assento no Conselho Gestor das APA, onde eram discutidas diversas questões relativas à agricultura ali praticadas.

Em função das trocas e da quantidade de projetos existentes, a Secretaria do Verde e do Meio Ambiente (SVMA) realizou o Primeiro Encontro das ONG atuantes na região, atividade construída em parceria com a ITCP-USP, com o objetivo de mapear os diferentes projetos e construir uma rede de articulação e colaboração entre eles. A partir dessa iniciativa foram realizadas algumas atividades em parceria entre as diferentes ONG ali atuantes, o que fortaleceu ainda mais a agricultura de base agroecológica praticada.

No que se refere à presença da ITCP-USP, dois projetos marcaram sua atuação no território, com resultados presentes ainda hoje. O primeiro, Hortas Solidárias, realizado entre os anos de 2006-2007, resultado de uma parceria entre a ITCP, o Núcleo de Ensino e Pesquisa Aplicada de Fortaleza-CE (Nepa) e a Associação Pequeno Príncipe (APP) em Parelheiros, tinha por objetivo di- 
fundir práticas de produção agroecológica entre os agricultores urbanos locais e construir um Centro de Referência em Agroecologia na região, com sede na Associação Pequeno Príncipe, situada próxima da subprefeitura de Parelheiros.

A equipe executora, inicialmente, percorreu a região mapeando os agricultores e convidando-os para participar do projeto. Uma vez por mês os integrantes - a equipe executora, os membros da Associação e cerca de 40 agricultores locais e de áreas limítrofes - encontravam-se na APP, onde participavam de oficinas compostas por atividades de sensibilização e conversão agroecológicas, ocasião em que eram apresentados aos princípios da agroecologia, com atividades teóricas e práticas. Também ocorriam visitas periódicas às áreas dos agricultores em esquemas de rodízio. No segundo ano, os participantes que eram cerca de vinte, entre agricultores e consumidores, aprendiam as técnicas e aplicavam-nas em suas áreas, e as dúvidas ou dificuldades enfrentadas e os resultados alcançados eram discutidos na oficina sucessiva.

$\mathrm{Na}$ fase final se iniciou a comercialização da produção através da venda casada entre oferta dos produtores e demanda dos consumidores, com preço construído por todos e intermediado pela equipe, aproveitando-se da experiência que o então coordenador do projeto possuía no assunto por ser o criador da Aliança Social. ${ }^{3} \mathrm{O}$ sucesso da primeira venda estimulou a ampliação da comercialização, mas houve percalços: o descompasso entre o aumento da oferta e a capacidade de consumo dos participantes, aliado à transformação do grupo de compras em uma feira, com realização inclusive da "xepa"; o reduzido poder aquisitivo de boa parte dos consumidores; o momento em que a comercialização ocorria (a última semana do mês); a falta de comprometimento por parte dos funcionários da APP com relação à manutenção da horta modelo; a imposição dos princípios da economia solidária para a comercialização sem que os participantes tivessem sido preparados para tal. Todos esses fatores, em maior ou menor proporção, acabaram gerando uma crise no projeto que culminou com a saída de parte dos integrantes do grupo e com a fragilização e ruptura da parceria com a APP, decidida no momento de avaliação final do projeto.

A partir de então, e em consenso com os agricultores que permaneceram - cerca de dez no total -, teve início a segunda fase de atuação da ITCP-USP na região, ocorrida por meio do projeto Mãosementes conectadas: tecendo a rede colaborativa agroecológica de Parelheiros, realizado no período 2008-2010. Diante das decisões tomadas pelo grupo, o projeto sofreu três alterações importantes no que se referia à forma de execução e encadeamento das atividades em relação à sua proposição inicial.

Primeiro, o acompanhamento das áreas que era mensal, tornou-se quinzenal a partir da chegada do agrônomo integrante da equipe. Segundo, as oficinas, de periodicidade mensal, passaram a ser realizadas nas áreas dos agricultores, em esquema de rodízio, com ordem definida a partir da disponibilidade do agricultor e da atividade a ser realizada. Terceiro, passou a se dar também a difusão de 
tecnologias populares como estufa geodésica, desidratador solar, fogão solar, banheiro seco, composteira, produção de adubo orgânico, minhocário etc., as quais foram implantadas nas áreas dos agricultores a partir da demanda apresentada. O equipamento construído/atividade realizada, em forma de mutirão, permanecia para o agricultor que cedia sua propriedade para a realização da oficina, mas o aprendizado era para todos e, à medida que o grupo se fortalecia, iniciou-se a organização espontânea de mutirões para replicar a construção do equipamento para os que a desejassem, abrindo inclusive a participação para outros agricultores não integrantes da equipe.

No segundo ano de execução do projeto, com o grupo mais estruturado, também o formato das oficinas sofreu alteração. No início, elas tinham a duração de um dia inteiro e eram voltadas para a formação dos agricultores. $\mathrm{Na}$ segunda fase, por proposta dos participantes, elas passaram a ser dividida em dois momentos: pela manhã, um mutirão realizado por todos nas terras do agricultor que recebia a oficina, em atividade por ele proposta e, após o almoço, um período de formação, sendo os temas definidos coletivamente de um mês para outro. Assim, à medida que o grupo ia ganhando autonomia, passava a demandar novas alterações na dinâmica inicialmente pensada, fato que, embora significasse mais trabalho para a equipe executora, foi visto como um resultado positivo do projeto.

No final de 2008, a Secretaria do Verde e do Meio Ambiente (SVMA) de São Paulo começou a atentar para a pulverização de projetos e ONG atuando na região e decidiu, em parceria com a ITCP-USP, realizar um seminário no templo Solo Sagrado de Guarapiranga da Igreja Messiânica de São Paulo, convidando para participar as ONG atuantes no território e os agricultores envolvidos nos projetos. O objetivo era realizar a apresentação das experiências agroecológicas existentes na região, visando a constituição de uma rede colaborativa entre as $\mathrm{ONG}$ e os agricultores, bem como a divulgação das experiências nas feiras das APA realizadas pela SVMA-SP.

O seminário evidenciou uma diversidade muito grande de ações no território, bem como a falta de diálogo entre os diferentes projetos ali existentes e, em alguns casos, a disputa por agricultores para comporem o quadro de beneficiários. Dois fatos ficaram claros naquele momento: de um lado, tratar-se de uma ação, na maior parte dos casos, feita de cima para baixo; de outro, a inviabilidade de construir um diálogo entre os diferentes projetos. Em outras palavras, o que parecia existir era uma prática "de mercado" no território: os projetos eram pensados no gabinete, sem adesão no território, e chegavam, de cima para baixo, disputando os agricultores. Isso foi gerando entre eles uma visão utilitarista dos projetos, e uma grande oscilação na participação dos agricultores nas atividades propostas, com uma alternância entre um projeto e outro, buscando entender onde era possível "ganhar mais". Isso era reflexo de uma ação, equivocada entendemos, de boa parte dessas ONG e, em alguns momentos, também da equi- 
pe da ITCP, e tinha como resultado uma formação fragilizada e incompleta para o agricultor que, ao oscilar de um projeto para outro, perdia a continuidade das ações e terminava, não raro, por abandonar o projeto.

Diante da dificuldade de construir a colaboração esperada, a SVMA passou a realizar, no início dos anos 2009, o fortalecimento das ações na área por meio de reuniões periódicas que geraram importantes discussões sobre como dar maior visibilidade à produção realizada nessa fração do território. Muitas propostas foram discutidas nas reuniões, parte delas realizadas no âmbito do Conselho Gestor das APA Capivari-Monos e Bororé-Colônia, tais como formas de agregar aos produtos um duplo valor: ser agroecológico e produzido na área das APA; a criação de um selo "APA" para os produtos e, junto com representantes da Supervisão Geral de Abastecimento (Abast) do município, foram discutidas estratégias para a comercialização, inicialmente com barracas em feiras convencionais e, posteriormente, com feiras específicas para os produtores agroecológicos (a primeira delas viria a ser a feira do Parque Burle Marx).

Foi o primeiro momento em que se reconheceu a existência de um grupo formado por vários agricultores agroecológicos, integrantes dos diferentes projetos então em curso, capaz de garantir o fornecimento, com a devida periodicidade e constância, de produtos para abastecer pelo menos uma barraca nas feiras locais. Existia, porém, um desafio a ser superado: garantir um planejamento e padronização da produção entre os diferentes agricultores, capaz de propiciar a diversificação e continuidade da produção para o fornecimento nas feiras. Nesse ponto, a atuação da ITCP-USP e de outras duas ONG que também se destacavam com sua ação no território, a 5Elementos e o Instituto Kairós, foi fundamental para ajudar a pensar formas de solucionar a questão. Tal iniciativa possibilitou aos agricultores locais a troca de experiências e o fortalecimento das iniciativas na região, num caráter mais colaborativo de fato.

No caso do projeto Mãosementes, o aumento quantitativo e qualitativo da produção e da confiança do grupo propiciou a constituição de um grupo de fato: o Cultivar (Figura 1), que se tornou fornecedor do grupo de consumo de produtos agroecológicos então existente na ITCP, o Grupo de Consumo Comerativamente, da Rede Sementes de Paz. A partir dessa experiência, por iniciativa dos próprios agricultores do Cultivar, tentou-se constituir um grupo de compras solidário nos moldes do Comerativamente, em Parelheiros. No final de 2009, o grupo participou do Edital Fema ${ }^{4} 06$ SEMA/SP, com uma proposta para trabalhar com Meliponários, envolvendo conservação da mata e educação ambiental (Projeto Motirõ da Jatai). A elaboração do projeto contou com a colaboração de parte da equipe da ITCP, mas sua proposição e execução ficou a cargo do Instituto Pedro Matajs. O projeto foi aprovado e suas atividades tiveram início em setembro de 2010, quando o Mãosementes chegou ao fim.

$\mathrm{Na}$ fase final, o grupo, já mais fortalecido, passou a fornecer alimentos ao restaurante do Solo Sagrado de Guarapiranga, já sem acompanhamento da 
ITCP. A equipe foi convidada para uma reunião em que o grupo apresentou essa possibilidade e consultou sobre a viabilidade. $\mathrm{O}$ grupo foi incentivado a assumir o desafio, com o alerta para a necessidade de assumirem o compromisso com o planejamento e padronização da produção de forma coletiva, pois qualquer falha comprometeria a comercialização do grupo. Essa foi a última ação da ITCP-USP no âmbito do projeto Mãosementes. Tratou-se de uma experiência importante que, com erros e acertos, deixou raízes na região e contribuiu para que políticas públicas pudessem ser pensadas para o fortalecimento de uma agricultura urbana agroecológica no município de São Paulo.

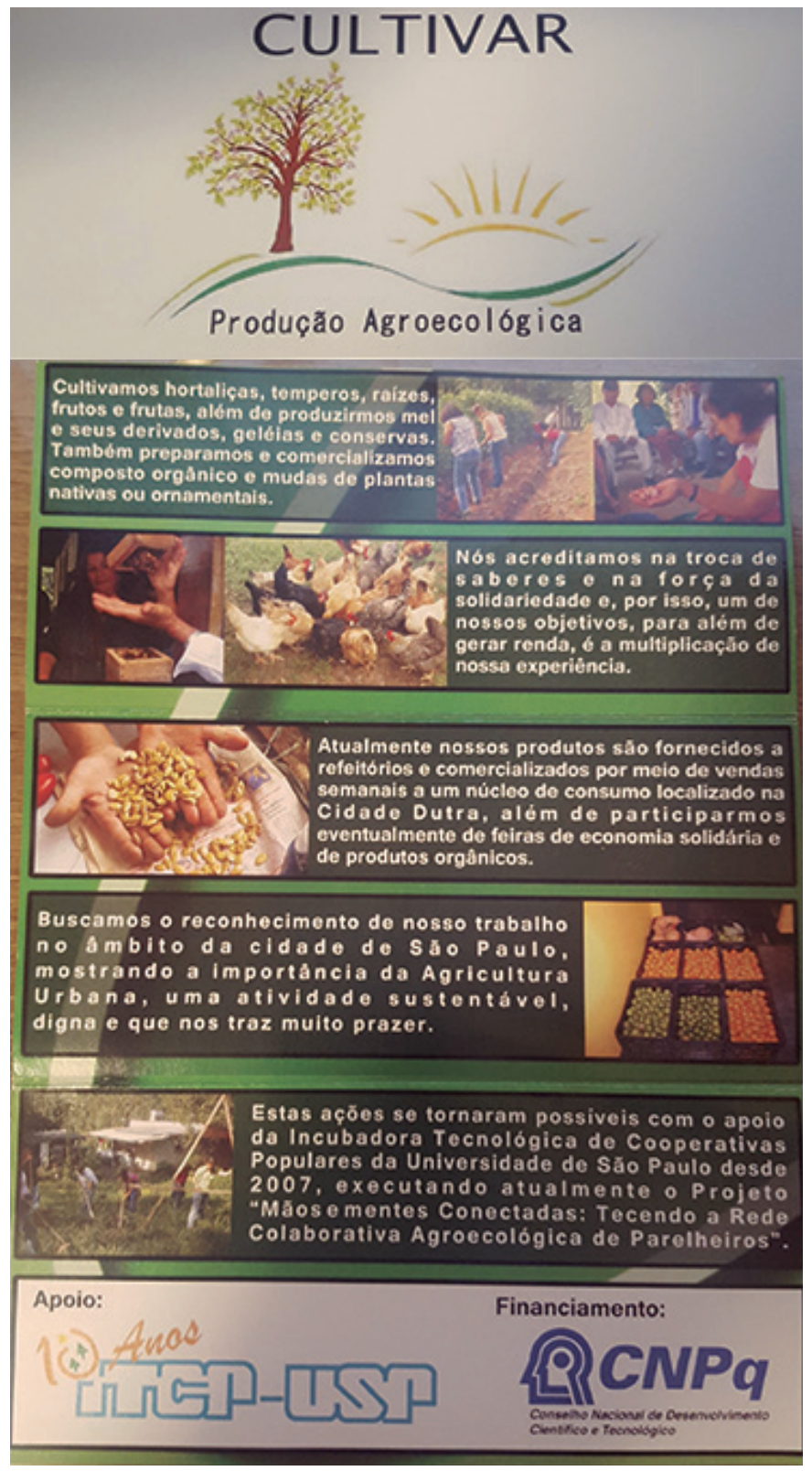

Figura 1 - Folder do Projeto Cultivar, realizado pelo ITCP-USP. 
Nesse contexto de grande efervescência e com o objetivo de consolidar a transição agroecológica na região e de ampliá-la para outras áreas foram lançados, em 2010, o Programa Agricultura Limpa e, por meio de decreto municipal, o Protocolo de Boas Práticas Agrícolas, em parceria com o governo estadual. Ambos serviam para incentivar a agricultura e a conversão agroecológica de agricultores. O Programa tinha como objetivo incentivar a agricultura e orientar a conversão da agricultura convencional para a agroecológica. O Protocolo era um documento ${ }^{5}$ com regras para que essa conversão ocorresse. O poder público oferecia apoio e assistência técnica para ajudar os agricultores na transição.

O Protocolo de Boas Práticas Agrícolas também permitia aos agricultores que pudessem vender seus produtos como "em transição". Dessa forma, o produto não era visto nem como convencional, nem como orgânico, porém, no momento da comercialização, o agricultor poderia cobrar um valor superior àquele cobrado pelo produto convencional. Isso foi feito para incentivar a produção agroecológica, pois geralmente os preços de produtos sem agrotóxicos são mais caros. Após o período de transição, que dura em média dois anos, o produto poderia ser considerado agroecológico.

Mesmo com a criação do Programa Agricultura Limpa e do Protocolo de Boas Práticas Agrícolas, os agricultores ainda tinham um outro problema: encontrar canais de comercialização para produtos orgânicos e agroecológicos. Por volta de 2010, ainda não existiam muitos locais que comercializavam esses produtos e a procura por eles era bem menor. Dessa forma, mais uma vez o poder público se envolveu, com a Supervisão Geral de Abastecimento do município, a CAE de Parelheiros e a Secretaria do Verde e do Meio Ambiente. Após muito diálogo e discussões sobre como criar esses canais, as primeiras feiras orgânicas e de agricultura limpa surgiram, dentro de parques municipais da cidade. A primeira delas foi no Parque Burle Marx, com apenas quatro barracas, e uma delas era da única cooperativa de agricultores do município de São Paulo, a Cooperativa Agroecológica dos Produtores Rurais e de Água Limpa da Região Sul de São Paulo (Cooperapas). Paralelamente a essas iniciativas, no final de 2010, a Associação Brasileira de Agricultura Biodinâmica (ABD) iniciou um projeto de certificação participativa com os agricultores do extremo sul, com dois grupos, um de Organização de Controle Social (OCS) e outro em sistema Sistema Participativo de Garantia (SPG), resultando na certificação de nove agricultores.

A criação da Cooperapas merece um destaque, pois essa cooperativa surgiu em um contexto de atuação da CAE de Parelheiros, das ONG e da ITCP-USP. Com o desenvolvimento de vários projetos nessa região do município, houve um aumento do interesse dos agricultores participantes em montar um grupo para a comercialização, pois muitos deles são pequenos produtores e não têm condições de assumir vendas expressivas e com regularidade. Assim, uma saída seria a formação de um grupo formalizado, como uma associação ou cooperativa. Outro motivo desse interesse era o de possibilitar aos agricultores participar 
de programas federais de compra de alimentos, como o Programa de Aquisição de Alimentos (PAA) e o Programa Nacional de Alimentação Escolar (PNAE).

A CAE acompanhava esses agricultores e suas discussões. O próprio poder público tinha interesse na criação de uma cooperativa, tanto que ele teve uma intervenção direta na formação da Cooperapas. De acordo com o relato de um funcionário que trabalhava na época na CAE, Cristiano Mendes, foi fornecido todo o apoio possível para o surgimento de uma cooperativa. Após reuniões e a manifestação de interesse dos agricultores, “[...] finalmente uma assembleia foi marcada, durando o dia inteiro, com o intuito de criar a Cooperapas. Mendes relata que foi feito de tudo para facilitar a criação da cooperativa. A Supervisão Geral de Abastecimento (Abast) pediu para seu advogado assinar o estatuto e seu contador ajudar com a abertura da cooperativa, dando entrada no CNPJ e na inscrição estadual, entre outros documentos necessários" (Nakamura, 2017, p.185). Dessa forma, surgia em 9 de junho de 2011, com 28 agricultores, a Cooperapas.

Após a criação da feira do Burle Marx, outros grupos variados, envolvidos com a agricultura orgânica e agroecológica, como a Associação de Agricultura Orgânica (AAO), a ABD, a Fundação Mokiti Okada, o Instituto Kairós, entre outros, começaram a participar das discussões, a fim de que mais feiras fossem criadas. Com isso, surgiram várias feiras orgânicas hoje importantes no cenário da cidade de São Paulo, entre as quais a Feira do Modelódromo do Ibirapuera. ${ }^{6}$

Em 2014, com a aprovação do novo Plano Diretor no governo de Fernando Haddad, a criação de uma zona rural refletiu o interesse e a atuação das ONG, de ativistas, agricultores e do próprio poder público, pela defesa da agricultura e de sua ampliação e manutenção no extremo sul do município de São Paulo, com seus mananciais e vegetação nativa. A maior extensão de zona rural está nessa região do município (Figura 2).

O Plano Diretor de 2014 enfatizou a importância da zona rural como uma área de beneficiamento da produção agrícola, de barreira para expansão da mancha urbana e de conservação dos serviços ambientais, sobretudo a produção de água (Câmara Municipal de São Paulo, 2014, p.40). Para incentivar a conservação dessa região, o plano aposta na criação de uma zona rural multifuncional, ou seja, um rural que se dedica não apenas à agricultura, como também a outras atividades com possibilidade de geração de renda, como o turismo. Para isso, foi criado um Polo de Ecoturismo de São Paulo, com propostas de roteiros que oferecem como atividades visitas a agricultores, a centros ecumênicos, aldeias indígenas, cachoeiras, mirantes, entre outros (Polo de Ecoturismo de São Paulo, 2020).

Deve-se destacar que a delimitação de uma zona rural no município foi resultado tanto das políticas e projetos voltados para a agricultura dessa região desenvolvidos ao longo da década dos anos 2000 e início de 2010, e que resultaram no surgimento da CAE de Parelheiros, do Programa Agricultura Limpa e do Protocolo de Boas Práticas Agrícolas, da criação da Cooperapas, quanto do interesse do poder público em conservar os mananciais e a vegetação nativa 


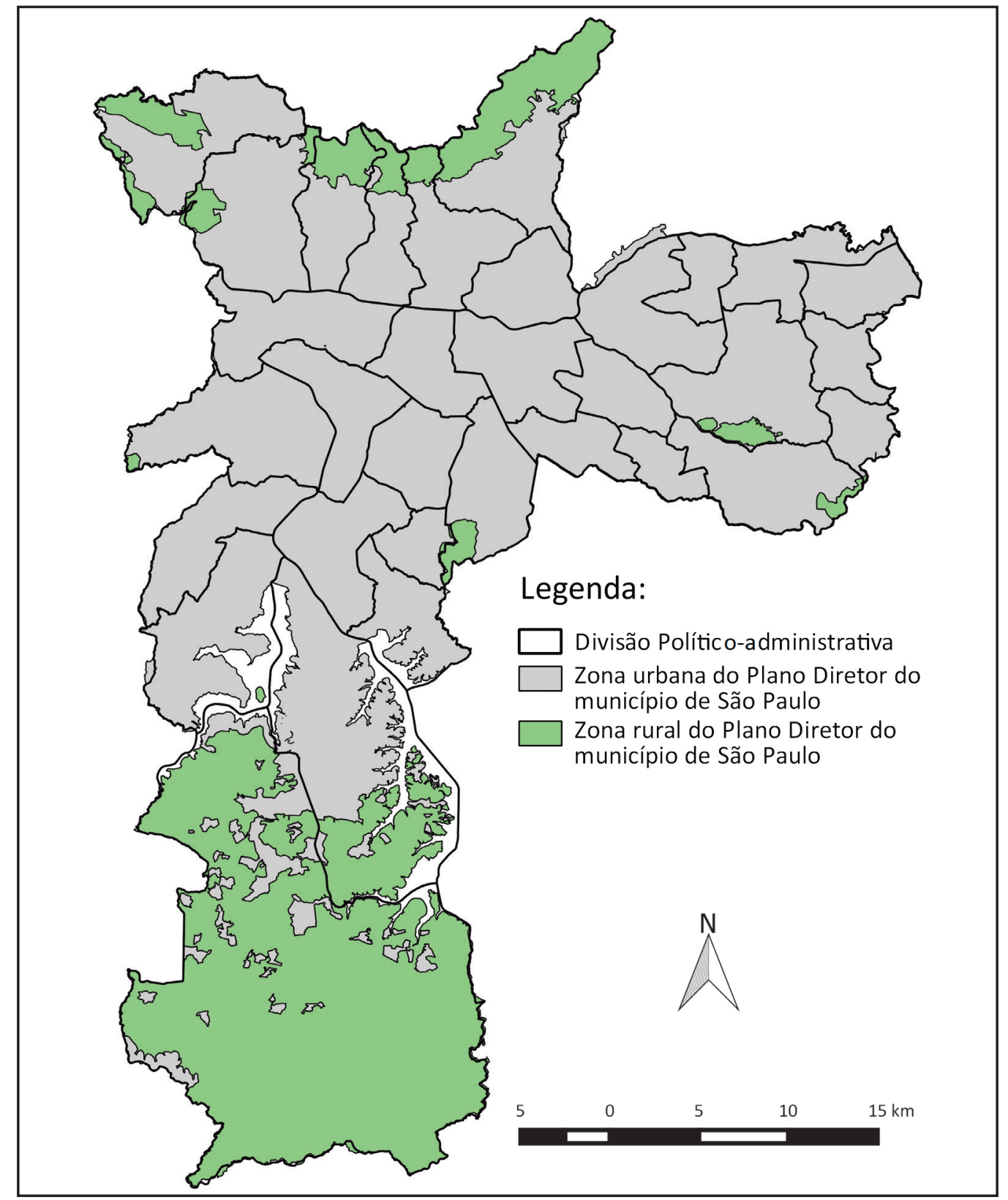

Fonte: Prefeitura de São Paulo, 2014 (Crédito: Rafael Calabria).

Figura 2 - Mapa do município de São Paulo, com a zona urbana e a zona rural.

dessa região, tentando diminuir e barrar a expansão da mancha urbana. Com essa intenção já tinham sido criadas duas Áreas de Proteção Ambiental (APA), a APA Capivari-Monos em 2004, e a APA Bororé-Colônia em 2006. Essas áreas protegidas preveem atividades econômicas e a presença de pessoas vivendo nos seus territórios. A criação do Protocolo de Boas Práticas Agrícolas e do Programa Agricultura Limpa, inclusive, deu-se pela intenção de se conservar a região e, ao mesmo tempo, permitir uma atividade econômica capaz de ser menos 
prejudicial ao meio ambiente. A delimitação da zona rural no Plano Diretor de 2014 deixa tão explícito o interesse do poder público em vincular o rural a uma ideia de conservação ambiental que a área rural do extremo sul do município coincide, em quase sua totalidade, com as áreas das duas APA.

É inegável a importância desse novo Plano Diretor ao delimitar uma zona rural e se voltar também para a agricultura no município. Uma zona rural em um município com a maior metrópole brasileira não deixa de ser uma inovação no modo de se pensar o urbano, a cidade e seu planejamento e legislação. Entretanto, ele deixa de lado outras questões cruciais presentes na região, como a questão fundiária (fortemente presente, pois ainda existem posseiros, além de muitos loteamentos ilegais e pouca ação efetiva do poder público para regularizar a situação); as atividades produtivas e suas múltiplas dimensões, tais como o perfil dos sujeitos ali presentes, o tipo de produção e comercialização existente, o tamanho das propriedades e suas limitações e a ainda forte presença da agricultura convencional e das problemáticas dela decorrentes, ignorada pelo Plano que destaca a existência apenas de uma agricultura agroecológica.

Após a aprovação desse Plano Diretor em 2014, outros avanços ocorreram para o desenvolvimento da agricultura no extremo sul do município de São Paulo. Em 2016, a prefeitura lançou o Agriculturas Paulistanas, com a intenção de realizar a regularização fundiária por meio de uma parceria com o Instituto Nacional de Colonização e Reforma Agrária (Incra), bem como de proporcionar a capacitação técnica para agricultores da região e de dar acesso gratuito a equipamentos para a atividade agrícola. Foram comprados um trator, um microtrator com kit encanteirador, uma enxada rotativa com encanteirador, uma carreta agrícola basculante, um sulcador, um perfurador de solo, um terraceador de arrasto, uma roçadeira hidráulica, uma pá agrícola traseira e um distribuidor de fertilizantes. Infelizmente, com a troca de gestão, ocorrida em 2017, o programa não teve a sua devida continuidade. $O$ trator, por exemplo, não tem a manutenção necessária e é muito solicitado. É recorrente a reclamação de agricultores sobre as dificuldades de uso deste equipamento, que, além disso, mal atende os produtores da região.

Por sua vez, um grande passo dado para o fortalecimento da agricultura urbana, elogiado por representantes da sociedade civil, academia e ativistas envolvidos com a agricultura urbana, foi a regulamentação da Lei n.16.140 em 5 de abril de 2016, que tornou obrigatória a inclusão de alimentos orgânicos ou de base agroecológica na alimentação escolar municipal. Em 20 de maio do mesmo ano, foi lançado o Decreto n.57.007, o qual instituiu a Política Municipal de Segurança Alimentar e Nutricional (PMSAN) e fixou diretrizes para o Plano Municipal de Segurança Alimentar e Nutricional. Também é interessante destacar que ocorreu, ainda em 2016, uma série de pré-conferências, incluindo uma no distrito de Parelheiros, como preparação para a $1^{\text {a }}$ Conferência Municipal de Desenvolvimento Rural Sustentável, realizada em junho daquele ano. 
Após a troca de gestão dos anos 2016 para 2017, a atenção voltada à agricultura urbana diminuiu. Houve algumas iniciativas que tinham ligação com a agricultura, como o surgimento do Programa Alimento Saudável, o qual busca a continuidade e o aperfeiçoamento da lei que tornou obrigatória a inserção de alimentos orgânicos na merenda municipal escolar e amplia as opções de frutas, carnes, hortaliças e verduras. Um aspecto positivo desse programa foi o aumento das hortas pedagógicas em escolas, saltando de $351 \mathrm{em} 2016$ para $592 \mathrm{em}$ 2017 (Cidade de São Paulo, 2017).

A esse propósito, um programa ganhou destaque e se tornou uma das apostas para o desenvolvimento da região e da atividade agrícola na gestão Fernando Haddad: o Ligue os Pontos. Esse programa foi o ganhador do prêmio Mayors Challenge, uma iniciativa da Bloomberg Philanthropies, ${ }^{7}$ que premia iniciativas inovadoras de cidades para melhorar a qualidade de vida das pessoas. Tal premiação, no valor de US\$ 5 milhões, ocorreu no final da gestão de Haddad em 2016.

O programa passou por dificuldades de implantação com a mudança de gestão, ocorrida no ano seguinte. Iniciada com João Dória, entre 2017 e 2018, houve uma reestruturação administrativa neoliberalista, o que levou o Ligue os Pontos a um impasse e imobilização, pois a agricultura não era prioridade nesse governo. Posteriormente, a prefeitura foi assumida por Bruno Covas, ${ }^{8}$ vice de Dória. Como o programa tinha muita visibilidade e o montante ganho era alto, ele ganhou mais impulso com a gestão de Covas e passou a ser implementado, com ações mais concretas para os agricultores e a região do extremo sul (Gomes; Da Cruz, 2019). Entre as ações realizadas estão: uma parceria com o programa Teia para a criação de um espaço de coworking no Parque Nascentes do Ribeirão Colônia; o financiamento para oito projetos de agricultores da região, no valor de R\$ 35 mil para cada um; a implantação de sistemas ecológicos de esgoto junto com o escritório cooperativo Sapiência Ambiental para agricultores.

O Programa Ligue os Pontos ainda está em andamento e desenvolvendo ações que buscam criar uma produção mais fortalecida e independente de alimentos agroecológicos nessa região do município de São Paulo. Um dos resultados mais aguardados do programa é a coleta de dados que está sendo realizada a respeito de aspectos variados da região, como sobre a agricultura, o perfil dos moradores e das aldeias indígenas, de outras atividades econômicas da região como o turismo etc.

\section{Considerações finais}

Como buscamos discutir, a presença da agricultura urbana no extremo sul do município de São Paulo não é recente, mas sua visibilidade e importância tem alcançado cada vez mais destaque. A partir dos anos 2000 , e com mais intensidade a partir dos anos 2010, muitas iniciativas ganharam corpo e assinalaram no território mudanças significativas. A atuação das ONG e da Universidade de São Paulo, com projetos buscando a difusão de práticas agroecológicas e de valoriza- 
ção da agricultura ali existente, levou à expansão dos agricultores que realizaram a transição da agricultura convencional para aquela agroecológica, e de tantos outros que passaram a se dedicar à agricultura já sob esse novo princípio.

A difusão desses projetos na região chamou a atenção da Secretaria do Verde e do Meio Ambiente, que passou a promover ações no intuito de articulá-los. Se o objetivo não foi de início alcançado, a iniciativa concretizada em um seminário realizado no espaço do Solo Sagrado permitiu dar visibilidade às inúmeras iniciativas presentes no território, bem como ao número de agricultores envolvidos nas diversas iniciativas de transição agroecológica e a uma construção de articulações possíveis entre projetos específicos. Outro ganho do seminário foi ter permitido a ampliação das discussões entre as ONG, USP, Secretaria do Verde e do Meio Ambiente, Supervisão Geral de Abastecimento, entre outros, na busca de canais de comercialização para a produção agroecológica ali existente. Tais ações, por sua vez, serviram de base para as diferentes políticas públicas que surgiram no período, como o Protocolo de Boas Práticas Agrícolas e o Programa Agricultura Limpa. O surgimento de diferentes grupos de agricultores, a criação da Cooperapas, a ampliação do número de agricultores certificados por OCS ou SPG são prova da viabilidade dessa prática.

Para além das conquistas proporcionadas pelos diferentes projetos, é importante ter claro que muitas vezes eles são concebidos em gabinete para serem implantados no território sem prévio contato com os futuros beneficiários para conhecimento de sua realidade e reais demandas. Isso acaba gerando uma curiosidade inicial seguida ou de um abandono do projeto, comprometendo seu andamento, ou de uma relação de dependência em relação à equipe proponente, e consequentemente à perpetuação da ação da $\mathrm{ONG}$ ou da própria universidade no local, numa prática bastante assistencialista. $\mathrm{O}$ verdadeiro objetivo, em nosso entender, de uma atividade que vise promover a autonomia dos beneficiários, pelo menos no que se refere aos projetos de extensão executados pela universidade deveria ser, após o conhecimento prévio da realidade local, construir projetos que visem contemplar as demandas presentes no território e que sejam capazes de permitir uma troca/apropriação real do conhecimento e de levar à autodeterminação dos envolvidos. Esse é o verdadeiro desafio dos projetos implantados também pelo poder público voltados ao fortalecimento da agricultura urbana no município.

Agradecimentos - O Projeto Mãosementes conectadas: tecendo a rede colaborativa agroecológica de Parelheiros teve coordenação da Profa. Dra. Valeria de Marcos (DG FFLCH-USP/GEAU-IEA-USP) e foi possível graças ao Edital MCT/CNPq/MDA/ SAF/MDS/SESAN 036/2007 no período 2007-2010.

À Capes, pelo financiamento da pesquisa por meio de bolsa de mestrado e, atualmente, de doutorado da autora Angélica Campos Nakamura. 
1 É bom ter claro que antes da intensificação do processo de urbanização do município de São Paulo, a atividade agrícola era muito presente nas diferentes regiões do município e tinha por finalidade garantir tanto o consumo das famílias que se dedicavam a ela quanto o abastecimento do mercado local, caracterizado sobretudo por pequenas quitandas e posteriormente pelas feiras livres (a primeira feira livre data de 1918, mas apenas em 1948 uma regulamentação determinou que todos os bairros deveriam ter sua própria feira). Esse passado rural da cidade encontra-se nos nomes dos bairros e das ruas: Chácara do Gal. Arouche, Chácara D. Angélica, Chácara do Bexiga, Chácara do Bom Retiro, Sítio Pacaembu, Viaduto do Chá, Avenida Jacu-Pêssego, Rua do Bananal etc. À medida que a urbanização vai se intensificando ocorre uma pressão sobre essas áreas, e a atividade agrícola passa a ser deslocada para a periferia do município enquanto as áreas mais centrais passam a ter outros usos (habitacionais, comerciais etc.) (Oliveira, 2004).

2 Com a aprovação do Estatuto da Cidade, por meio da Lei n.10.257 de 10 de julho de 2001, estabeleceram-se instrumentos para a política pública urbana, entre eles, a importância e a necessidade dos Planos Diretores. Assim, em 2002, São Paulo aprova esse novo Plano Diretor. Existiram outros planos, que chegaram a ser elaborados, mas sempre acabavam engavetados, como ocorreu com o Plano Diretor elaborado na passagem da gestão Mario Covas (1982-1985) para a de Jânio Quadros (1985-1989); e de Luiza Erundina (1989-1993) para a de Paulo Maluf (1993-1997).

3 Uma experiência de grupo de compra solidário que colocava em contato produtores e consumidores, selando entre eles um compromisso de compra e venda dos produtos, com a construção do preço justo estabelecida em acordos mútuos entre produtores e consumidores. É uma variante das experiências da Comunidade que Sustenta a Agricultura (CSA), também existente em diversas partes do mundo e em São Paulo.

4 O Fundo Especial de Meio Ambiente e Desenvolvimento Sustentável (Fema) “destina-se a apoiar projetos que visem o uso sustentável dos recursos naturais, manutenção, melhoria e/ou recuperação da qualidade ambiental, pesquisa e atividades ambientais de controle, fiscalização e defesa do meio ambiente" (Cidade de São Paulo, 2020).

5 Atualmente, existe um Protocolo de Transição Agroecológica, porém, emitido apenas pela Secretaria Estadual do Meio Ambiente, e não mais um protocolo com uma parceria dos governos estadual e municipal.

6 A feira é popularmente conhecida como Feira do Ibirapuera. Ela ocorria em uma área considerada pertencente ao Parque do Ibirapuera, conhecida como Modelódromo. A partir de 2016, a feira começou a enfrentar problemas por ocorrer em uma área dentro do parque. Nos últimos anos, ela ocorre em frente ao Modelódromo, na Rua Curitiba.

7 A Bloomberg Philanthropies é uma instituição filantrópica estadunidense, cuja sede é em Nova York. Seu fundador é Michael R. Bloomberg. A instituição tem um fundo de doações de caridade e esses recursos são destinados a áreas do meio ambiente, saúde pública, artes, inovação do governo e educação.

8 João Dória venceu as eleições para a Prefeitura Municipal de São Paulo no final de 2016. Assumiu o cargo de prefeito no ano seguinte, porém, saiu para concorrer as eleições para o governo do estado de São Paulo em 2018. Dória conseguiu vencer as eleições estaduais, tornando-se governador em 2019. Seu vice, Bruno Covas, foi quem assumiu a prefeitura a partir de então. 
Referências

CÂMARA MUNICIPAL DE SÃO PAULO. Conbeça o novo Plano Diretor Estratégico de São Paulo. Lei 16.050/14. São Paulo: Câmara Municipal de São Paulo, 2014.

CIDADE DE SÃO PAULO. Proaurp. 2013. Disponível em: <https://www.prefeitura.sp.gov.br/cidade/secretarias/meio_ambiente/servicos/proaurp/index. php?p=3009l>. Acesso em: 4 mar. 2020.

Programa Alimento Saudável amplia hortas educativas e compra de orgânicos na merenda, 27 nov. 2017. Disponível em: <https://www.prefeitura.sp.gov.br/cida$\mathrm{de} /$ secretarias/subprefeituras/sapopemba/noticias/?p=78639>. Acesso em: 6 mar. 2020 .

Fema. Disponível em: <https://www.prefeitura.sp.gov.br/cidade/secretarias/meio_ambiente/confema/index.php?p=3299>. Acesso em: 8 mar. 2020.

COSTA, E. V. da. Cotia e Itapecerica da Serra, subúrbios agrícolas. In: AZEVEDO, A. de. (Org.) A cidade de São Paulo: estudos de Geografia Urbana. São Paulo: Cia. Editora Nacional, 1958. v.IV: Os subúrbios paulistanos. p.109-152.

GOMES, L. A. C.; DA CRUZ, C. Towards a sustainable, circular and resilient urban agriculture in São Paulo? The "Ligue os Pontos" program. In: UDM Forum 2019: Quels urbanismes de transition?, 2019.

INSTITUTO PEDRO MATAJS. Projeto Motirõ da Jataí. Disponível em: <http:// www.institutopedromatajs.org.br/Projeto\%20Motirõ\%20da\%20Jataí.htm>. Acesso em: 11. abr. 2020.

MARCOS, V. de. Mãosementes conectadas: tecendo a rede colaborativa agroecológica de Parelheiros. Relatório Técnico Final CNPq. São Paulo, 2013. 201p.

NAKAMURA, A. C. Cooperapas: agricultura e cooperativismo no extremo sul do município de São Paulo. São Paulo, 2017. 303f. Dissertação (Mestrado em Geografia Humana) - Faculdade de Filosofia, Letras e Ciências Humanas, Universidade de São Paulo.

OLIVEIRA, A. U. de. São Paulo: dos bairros e subúrbios rurais às bolsas de mercadorias e de futuros. In: OLIVEIRA, A. U.; CARLOS, A. F. A. (Org.) Geografias de São Paulo. São Paulo: Contexto, 2004. v.2. p.123-61.

PENTEADO, A. R. Os subúrbios de São Paulo e suas funções. In: AZEVEDO, A. de. (Org.) A cidade de São Paulo: estudos de Geografia Urbana. São Paulo: Cia. Editora Nacional, 1958. v.IV: Os subúrbios paulistanos, p.5-60.

POLO DE ECOTURISMO DE SÃO PAULO. Disponível em: <http://www.cidadedesaopaulo.com/ecoturismo>. Acesso em: 6 mar. 2020.

RESUMO - A partir dos anos 2000, diversas ações voltadas para a agricultura urbana e periurbana no município de São Paulo surgiram e ganharam força, impactando diretamente a atividade agrícola da maior metrópole brasileira. No extremo sul, houve a atuação do poder público, da Universidade de São Paulo e de diversas ONG, o que levou ao incentivo da prática agroecológica, ao surgimento da única cooperativa de agricultores 
paulistanos, a Cooperapas, e à ampliação da produção e comercialização de alimentos agroecológicos para a cidade de São Paulo.

PALAVRAS-CHAVE: Agricultura urbana, Agricultura periurbana, São Paulo, Agricultura, Agricultores, Política pública, Cooperapas, Agroecologia

ABSTRACT - Since the 2000s, several actions focused on urban and peri-urban agriculture in the city of São Paulo emerged and gained strength, directly impacting on the agricultural activity of the largest Brazilian metropolis. In the extreme south, the government, the University of São Paulo and several NGOs carried out actions that encouraged agroecological practices, the emergence of the only cooperative of farmers in São Paulo, Cooperapas, and the expansion of the production and commercialization of agroecological foods for the city of São Paulo.

KEYWORDs: Urban agriculture, Periurban agriculture, São Paulo, Agriculture, Farmers, Public policy, Cooperapas, Agroecology.

Angélica Campos Nakamuraé doutoranda em Geografia Humana pela Universidade de São Paulo (USP). Bolsista do Programa de Pós-Graduação em Geografia Humana da Faculdade de Filosofia, Letras e Ciências Huamanas (FFLCH/USP) pela Capes. Membro do Grupo de Estudos de Agricultura Urbana (GEAU) do Instituto de Estudos Avnçados da USP. @ - angelicanakamura.geo@gmail.com /

https://orcid.org/0000-0001-8102-2188.

Valeria de Marcos é doutora em Geografia e Planejamento Territorial para a Valorização do Patrimônio Histórico e Ambiental pela Università degli Studi di Genova, Itália. Professora do Departamento de Geografia e do Programa de Pós-Graduação em Geografia Humana da Faculdade de Filosofia, Letras e Ciências Huamanas (FFLCH/USP). Membro do Grupo de Estudos de Agricultura Urbana (GEAU) do Instituto de Estudos Avnçados da USP. @-demarcos.vale@usp.br /

https://orcid.org/0000-0002-9633-7323.

Recebido em 10.9.2019 e aceito em 20.4.2020.

I, II Universidade de São Paulo, Faculdade de Filosofia, Letras e Ciências Huamanas, São Paulo, Brasil. 